\title{
LOW TEMPERATURE GROWTH OF ULTRANANOCRYSTALLINE DIAMOND ON GLASS SUBSTRATES FOR FIELD EMISSION APPLICATIONS*
}

\author{
T. D. Corrigan 1,2, A. R. Krauss², D. M. Gruen², O. Auciello ${ }^{3}$, and R.P.H. Chang ${ }^{1}$
}

1 Department of Materials Science and Engineering, Northwestern University, Evanston, II 60208 2Materials Science and Chemistry Divisions, Argonne National Laboratory, Argonne, IL 60439 3Materials Science Division, Argonne National Laboratory, Argonne, II 60439

submitted for publication in the

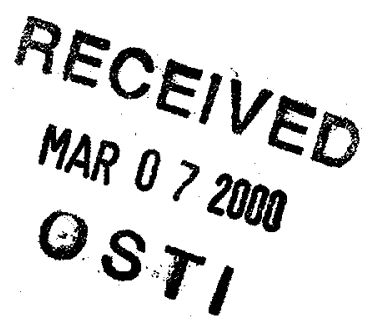

Proceedings of the Amorphous and Nanostructured Carbon Symposium

Materials Research Society Fall 1999.Meeting

November 29-December 2, 1999

Boston, Massachusetts

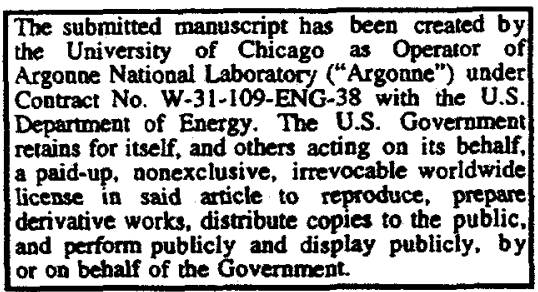

*Work supported by the U.S. Department of Energy, BES-Materials Sciences, under Contract W-31-109-ENG-38, by DARPA/ONR under Contract N00014-97-F-005. 


\section{DISCLAIMER}

This report was prepared as an account of work sponsored by an agency of the United States Government. Neither the United States Government nor any agency thereof, nor any of their employees, make any warranty, express or implied, or assumes any legal liability or responsibility for the accuracy, completeness, or usefulness of any information, apparatus, product, or process disclosed, or represents that its use would not infringe privately owned rights. Reference herein to any specific commercial product, process, or service by trade name, trademark, manufacturer, or otherwise does not necessarily constitute or imply its endorsement, recommendation, or favoring by the United States Government or any agency thereof. The views and opinions of authors expressed herein do not necessarily state or reflect those of the United States Government or any agency thereof. 


\section{DISCLAIMER}

Portions of this document may be illegible in electronic image products. Images are produced from the best available original document. 


\title{
LOW TEMPERATURE GROWTH OF ULTRANANOCRYSTALLINE DIAMOND ON GLASS SUBSTRATES FOR FIELD EMISSION APPLICATIONS
}

\author{
T. D. CORRIGAN ${ }^{1,2}$, A. R. KRAUSS ${ }^{2}$, D. M. GRUEN ${ }^{2}$, O. AUCIELLO ${ }^{3}$, AND R. P. H. CHANG ${ }^{1}$ \\ ${ }^{1}$ Dept. of Materials Science and Engineering, Northwestern University, Evanston, IL 60208 \\ ${ }^{2}$ Materials Science and Chemistry Divisions, Argonne National Laboratory, Argonne, IL 60439 \\ ${ }^{3}$ Materials Science Division, Argonne National Laboratory, Argonne, IL 60439
}

\section{ABSTRACT}

Recent studies of field emission from diamond have focused on the feasibility of growing diamond films on glass substrates, which are the preferred choice for cost-effective, large area flat panel displays. However, diamond growth on glass requires temperatures $\leq 500^{\circ} \mathrm{C}$, which is much lower than the temperature needed for growing conventional microwave plasma chemical vapor deposition (CVD) diamond films. In addition, it is desirable to minimize the deposition time for cost-effective processing. We have grown ultrananocrystalline diamond (UNCD) films using a unique microwave plasma technique that involves $\mathrm{CH}_{4}$ - $\mathrm{Ar}$ gas mixtures, as opposed to the conventional $\mathrm{CH}_{4}-\mathrm{H}_{2}$ plasma CVD method. The growth species in the $\mathrm{CH}_{4}-\mathrm{Ar} \mathrm{CVD}$ method are $\mathrm{C}_{2}$ dimers, resulting in lower activation energies and consequently the ability to grow diamond at lower temperatures than conventional CVD diamond processes. For the work discussed here, the UNCD films were grown with plasma-enhanced chemical vapor deposition (PECVD) at low temperatures on glass substrates coated with Ti thin films. The turn-on field was as low as $3 \mathrm{~V} / \mu \mathrm{m}$ for a film grown at $500{ }^{\circ} \mathrm{C}$ with a gas chemistry of $1 \% \mathrm{CH}_{4} / 99 \% \mathrm{Ar}$ at 100 Torr, and $7 \mathrm{~V} / \mu \mathrm{m}$ for a film grown at $350{ }^{\circ} \mathrm{C}$. UV Raman spectroscopy revealed the presence of high quality diamond in the films.

\section{INTRODUCTION}

Diamond thin films and related materials are being extensively investigated because their low threshold field electron emission properties make them desirable for use in cold cathodebased devices. Work has been done on diamond-coated Si and Mo tips, ${ }^{1,2,3}$ flat diamond films, ${ }^{4,5,6}$ and other structures for use in field emission displays (FEDs). Most manufacturers of FEDs use glass substrates to minimize fabrication costs and because of their scalability to large area displays. In addition, most FEDs are currently fabricated using field emission arrays (FEAs) consisting of field emitter tips (i.e., sharp Mo or Si conical features) located at the center of a hole in a metallic layer (gate) above the tips. A major problem with current FEA technology is that the threshold field for emission is relatively high, and the surface of the tips are susceptible to contamination, leading to emission instability, and in some cases to runaway discharges that can destroy large portions of the array. In addition, the fabrication of field emitter tips generally requires several high precision alignment steps, resulting in added cost. Therefore, it is desirable to develop FEAs on glass substrates based on flat field emitters with low threshold field and stable and uniform electron emission.

Conventional microwave plasma chemical vapor deposition (CVD) of diamond involves $\mathrm{CH}_{4}$ as a precursor in a large background of hydrogen. These films are typically grown at 800$1000^{\circ} \mathrm{C}$, which melts most glasses of interest for use in FEDs. At lower temperatures, the conventionally grown diamond has a very low growth rate and it can take up to 20 hours or longer to form a continuous film.

Previous studies of low temperature growth of UNCD films on Si substrates, using an $\mathrm{Ar} / \mathrm{CH}_{4}$ microwave plasma, indicated that the films grow with an activation energy of 5.85 $\mathrm{kcal} / \mathrm{mol}^{7}$. This is in agreement with the activation energy calculated from first principles theory for growth based on carbon dimer insertion directly into the diamond lattice. ${ }^{8-10}$ Conventional microwave CVD using $\mathrm{CH}_{4} / \mathrm{H}_{2}$ plasmas has typical activation energies in the range of 20-30 $\mathrm{kcal} / \mathrm{mol}$. In our CVD system, if one uses a substrate temperature of $800{ }^{\circ} \mathrm{C}$ and a $1 \% \mathrm{CH}_{4} / 99 \%$ $\mathrm{H}_{2}$ gas pressure of 100 Torr, we find a growth rate of $\sim 1 \mu \mathrm{m} / \mathrm{hr}$ for conventional 
microcrystalline (MCD) films, vs $\sim 0.25 \mu \mathrm{m} / \mathrm{hr}$ for the UNCD films grown with $1 \% \mathrm{CH}_{4} / 99 \%$ Ar. Using these growth rates at $800^{\circ} \mathrm{C}$, the experimentally measured activation energy of 5.85 $\mathrm{kcal} / \mathrm{mol}$ for UNCD, and an assumed activation energy value of $24 \mathrm{kcal} / \mathrm{mol}$ for the MCD films, an Arrhenius plot can be constructed as shown in Figure 1. This plot shows that the UNCD has a higher anticipated growth rate than $\mathrm{MCD}$ in the temperature regime below $\sim 650^{\circ} \mathrm{C}$. According to this calculation, the growth rate of the UNCD film is $\sim 100$ times that of $\mathrm{MCD}$ at $350^{\circ} \mathrm{C}$. In practice, we were unable to obtain measurable growth of continuous MCD films or to verify that the deposits were diamond using a $\mathrm{CH}_{4}-\mathrm{H}_{2}$ plasma at substrate temperatures below $\sim 500^{\circ} \mathrm{C}$.

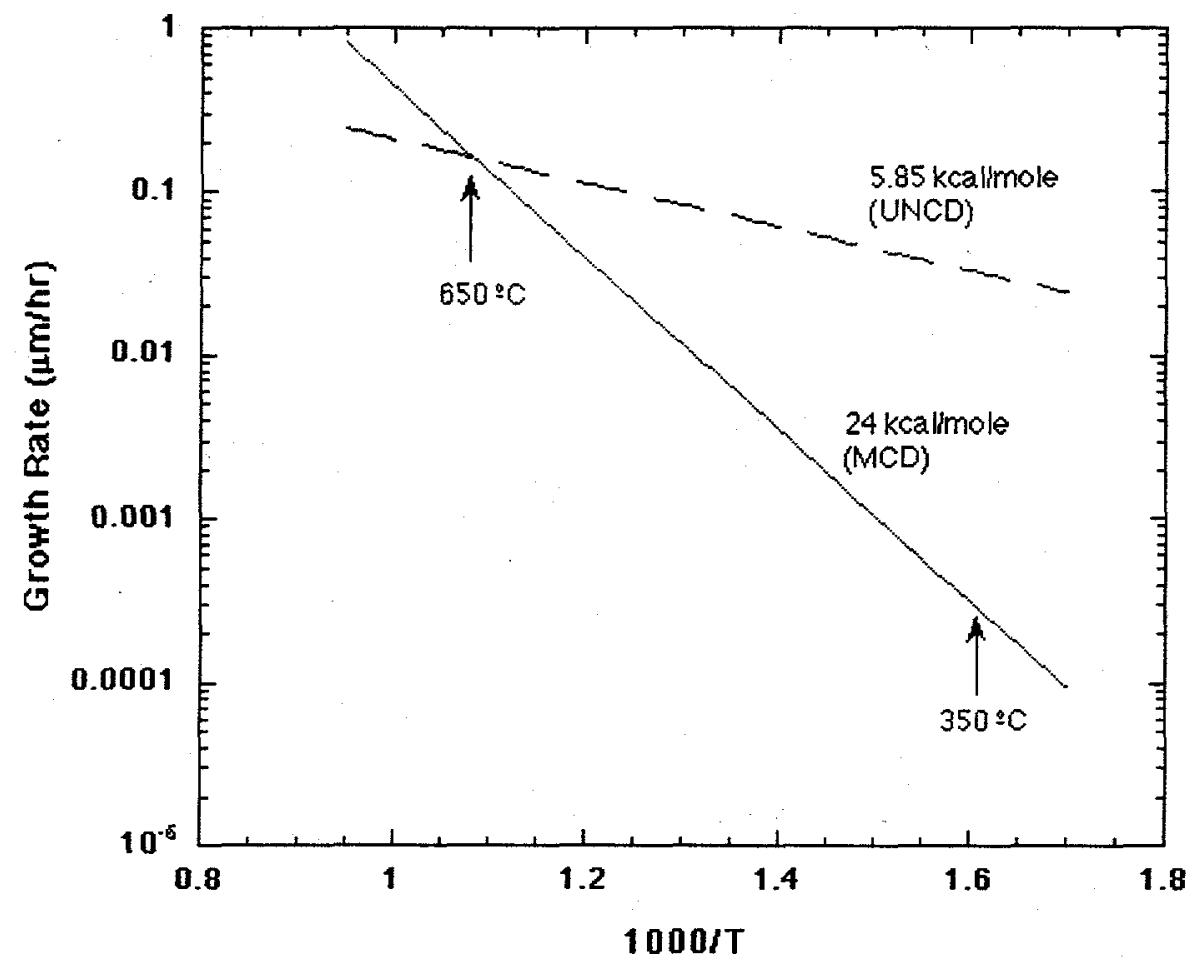

FIG. 1. Plot of the calculated growth rates vs reciprocal substrate temperature for UNCD and MCD films, using literature values for the activation energies.

\section{EXPERIMENTAL}

The UNCD films were grown on quartz glass slides coated with Ti layers (thickness: 200 $\mathrm{nm}$ ) produced by magnetron-sputter deposition. A diamond nucleation layer was formed using an ultrasonic bath with a suspension of diamond powder $(0.1$ micron particle size) for ten minutes. The films in this study were grown using an ASTeX PDS-17 2.45 GHz microwave plasma deposition system with $3.5 \mathrm{kw}$ rf induction substrate heater. The process gas used was a $1 \% \mathrm{CH}_{4}$ and $99 \% \mathrm{Ar}$ mixture, with a total flow of $100 \mathrm{sccm}$. The growth took place at a total power of 600 Watts and a pressure of 100 Torr. We grew films at various substrate temperatures from $350^{\circ} \mathrm{C}$ to $500^{\circ} \mathrm{C}$. The UNCD films were characterized using UV Raman spectroscopy at $266 \mathrm{~nm}$ wavelength. The electron emission properties of the films were characterized using a computer-controlled current vs. voltage measurement system ${ }^{6}$ involving an anode-cathode nominal gap of $50 \mu \mathrm{m}$.

\section{RESULTS AND DISCUSSION}

Figure 2 shows the UV Raman spectrum of UNCD films grown on Ti-coated quartz at substrate temperatures of 350 and $500^{\circ} \mathrm{C}$. The intensity of the $1332 \mathrm{~cm}^{-1}$ peak can be correlated with the $\mathrm{sp}^{3}$ bond content in the films, and is indicative of their highly crystalline nature. This is confirmed by the low intensity of the peak at $1580 \mathrm{~cm}^{-1}$, corresponding to a very low sp $\mathrm{s}^{2}$ bond content in the films. The Raman spectra indicate that there is very little degradation of the 
crystalline quality of the diamond films even at temperatures as low as $350{ }^{\circ} \mathrm{C}$. In this case, the UNCD films were grown with no additional heating applied via the substrate heater. and because of the plasma-induced surface heating, $350^{\circ} \mathrm{C}$ was the lowest achievable temperature. It should be noted that the film grown at $500^{\circ} \mathrm{C}$ is approximately twice as thick as the film grown at $350^{\circ} \mathrm{C}$ $(120 \mathrm{~nm}$ vs. $60 \mathrm{~nm})$, and that the $\mathrm{sp}^{2}: / \mathrm{sp}^{3}$ ratio is similar for the two films. The UV Raman data shown in Figure 2 are very similar to those obtained for films grown using the same plasma parameters at substrate temperatures of $800^{\circ} \mathrm{C}$, which have been demonstrated to be phase-pure diamond by a variety of experimental method ${ }^{s 3,6-9}$. Additional work using TEM will be carried out to further characterize the morphological properties of these low-temperature films.

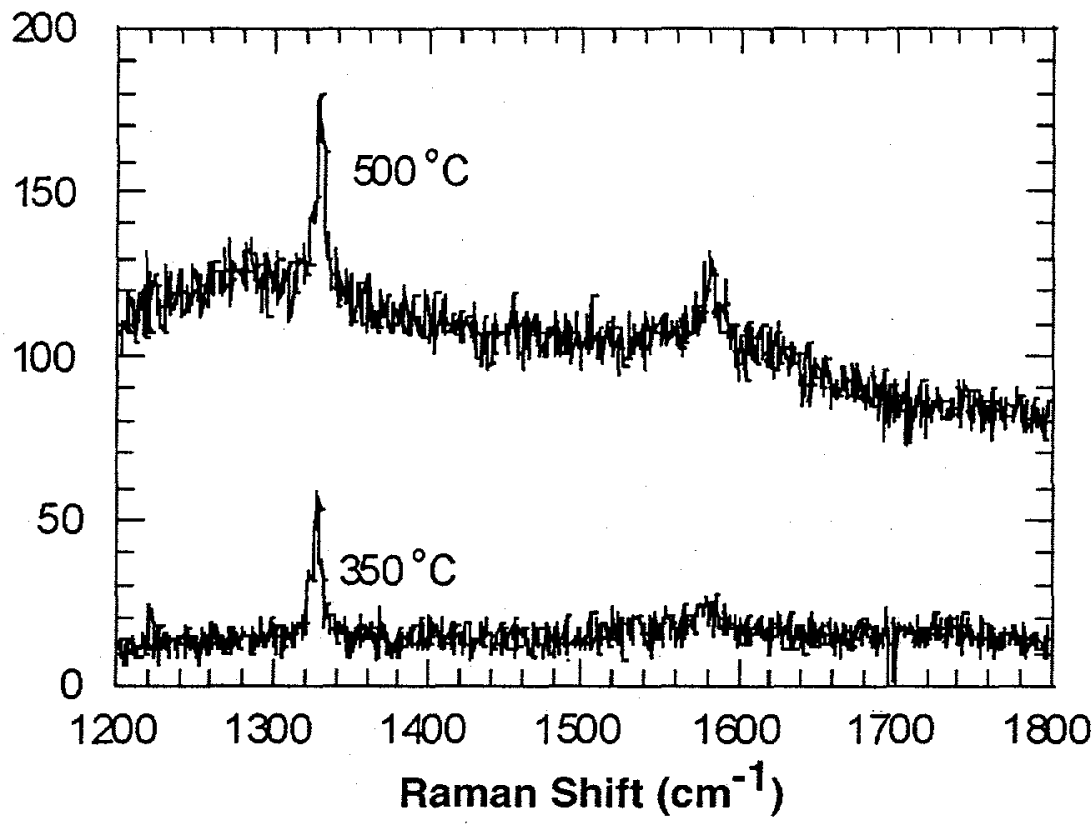

FIG. 2. UV Raman Spectroscopy of the UNCD films grown at $350^{\circ} \mathrm{C}$ and $500^{\circ} \mathrm{C}$, showing the sharp $\mathrm{sp}^{3}$ bonding at $1332 \mathrm{~cm}^{-1}$ indicating the presence of diamond.

The low-temperature UNCD films on Ti/quartz substrates exhibit excellent field emission properties, as shown in Figure 3 . The onset field is as low as $3 \mathrm{~V} / \mu \mathrm{m}$ for a film grown at $500^{\circ} \mathrm{C}$, and the average across the film is $5-8 \mathrm{~V} / \mu \mathrm{m}$. It should be noted that these films require no pre-

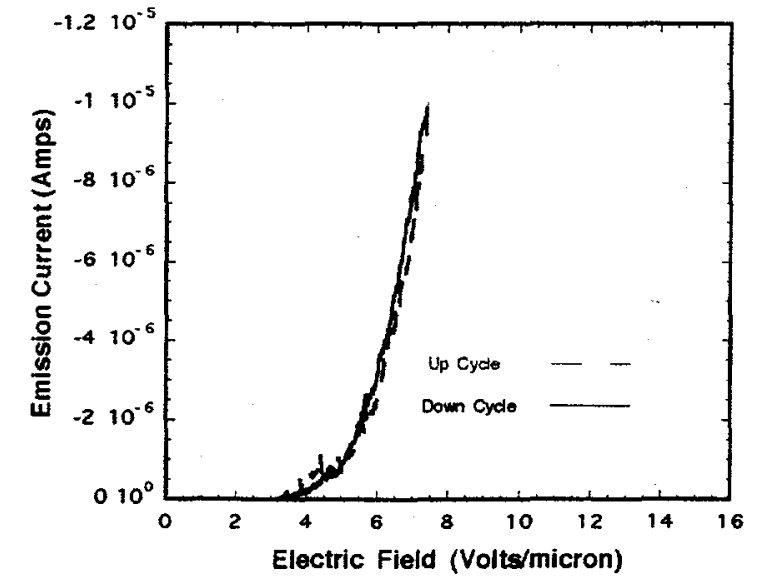

FIG. 3. Field emission of the film grown at $500^{\circ} \mathrm{C}$. Data represents an average of 5 cycles of increasing and 5 cycles of decreasing voltage.

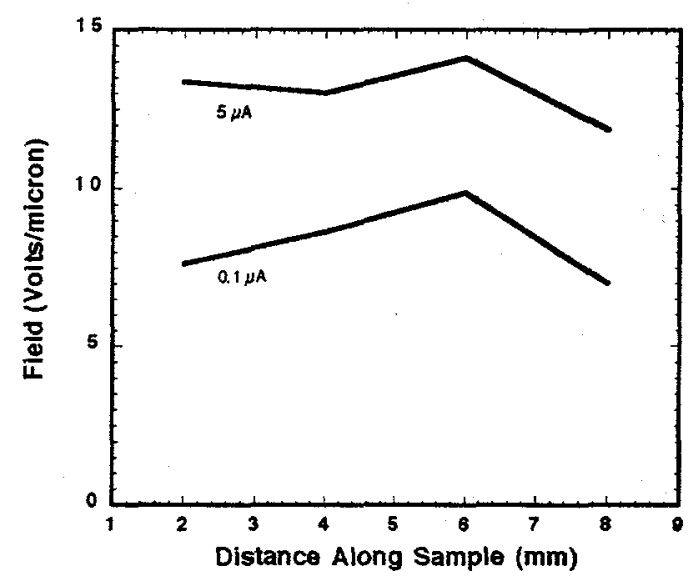

FIG. 4. Field required to retain a constant current of 0.1 $\mu \mathrm{A}$ and $5 \mu \mathrm{A}$, showing the uniformity of the field emission across a $1 \mathrm{~cm}^{2}$ sample. 
conditioning of the surface, exhibit little hysteresis between increasing and decreasing voltage cycles, and have a first-time turn-on behavior that is the same as succeeding measurements. The film grown at $350{ }^{\circ} \mathrm{C}$ exhibits uniform emission across a $1 \mathrm{~cm}^{2}$ area with onset fields in the 7-9 $\mathrm{V} / \mu \mathrm{m}$ range. Figure 4 shows the spatial uniformity of field emission for a film grown at $350^{\circ} \mathrm{C}$. The figure displays the fields required to obtain constant currents of $0.1 \mu \mathrm{A}$ and $5 \mu \mathrm{A}$. The field required for $5 \mu \mathrm{A}$ emission current varies less than $3 \mathrm{~V} / \mu \mathrm{m}$ across the entire $1 \mathrm{~cm}^{2}$ film. Measurement of the emission site density requires the use of a phosphor screen to image the entire emitting surface. This experiment is in preparation.

\section{CONCLUSIONS}

We have grown UNCD thin films on glass substrates at temperatures as low as $350{ }^{\circ} \mathrm{C}$. UV Raman analysis revealed that films grown at low substrate temperatures, using the same plasma parameters previously utilized in our laboratory for synthesizing high temperature phasepure nanocrystalline diamond films, also have a high $\mathrm{sp}^{3} \mathrm{vs} \mathrm{sp}^{2}$ relative content. These low temperature UNCD films exhibit threshold fields as low as $3 \mathrm{~V} / \mu \mathrm{m}$ for a film grown at $50{ }^{\circ} \mathrm{C}$, and $7 \mathrm{~V} / \mu \mathrm{m}$ for films grown at $350{ }^{\circ} \mathrm{C}$, with uniform field emission across a $1 \mathrm{~cm}^{2}$ sample. These results indicate that UNCD films can be integrated with glass substrates for fabrication of field emission displays and other cold cathode-based devices requiring cost-effective substrates.

\section{ACKNOWLEDGEMENTS}

This work was supported by the U.S. Department of Energy, BES-Materials Sciences under Contract W-31-109-ENG-38, and DARPA/ONR under Contract N00014-97-F-005.

\section{REFERENCES}

1. I. Brodie and C. A. Spindt, Vacuum Microelectronics, Adv. Electron. Phys. 83, 1 (1992).

2. E. I. Givargizov, V. V. Zhirnov, N. N. Chubun, and A. N. Stepanova, J. Vac. Sci. Technol. B 15,450 (1997).

3. T. G. McCauley, T. D. Corrigan, A. R. Krauss, O. Auciello, D. Zhou, D. M. Gruen, D.

Temple, R. P. H. Chang, S. English, and R. J. Nemanich in Covalently Bonded Disordered ThinFilm Materials, edited by M.P. Siegal, J.E. Jaskie, W. Milne, and D. McKenzie (Mater. Res. Soc. Proc. 498, Pittsburgh, PA 1998), p. 227.

4. C. Wang, A. Garcia, D. C. Ingram, M. Lake, and M. E. Kordesch, Electron. Lett. 27, 1459 (1991).

5. S. Jou, H. J. Doerr, and R. F. Bunshah, Thin Solid Films 280, 256 (1996).

6. D. Zhou, A. R. Krauss, T. D. Corrigan, L. C. Qin, T. G. McCauley, D. M. Gruen, R. P. H. Chang, and H. Gnaser, J. Appl. Phys. 82, 4546 (1997).

7. T. G. McCauley, D. M. Gruen, and A. R. Krauss, Appl. Phys. Lett. 73, 1646 (1998).

8. D. M. Gruen, S. Liu, A. R. Krauss, and X. Pan, J. Appl. Phys. 75, 1758 (1994).

9. D. M. Gruen, C. D. Zuiker, A. R. Krauss, and X. Pan, J. Vac. Sci. Technol. A 13, 1628 (1995).

10. P. C. Redfern, D. A. Horner, L. A. Curtis, and D. M. Gruen, J. Phys. Chem. 100, 11654 (1996). 